\title{
Lauric Acid
}

National Cancer Institute

\section{Source}

National Cancer Institute. Lauric Acid. NCI Thesaurus. Code C68384.

A saturated medium-chain fatty acid with a 12-carbon backbone. Lauric acid is found naturally in various plant and animal fats and oils, and is a major component of coconut oil and palm kernel oil. 